\title{
Cutaneous mastocytosis mimicking hypertrophic scars: A case report
}

\section{Faizan Younus Shah', Yasmeen Jabeen Bhat', Sumaya Zeerak¹, Roohi Wani², Iffat Hassan Shah ${ }^{1}$}

${ }^{1}$ Department of Dermatology, Government Medical College, Srinagar, Kashmir University, J\&K, India, ${ }^{2}$ Department of
Pathology, Government Medical College, Srinagar, Kashmir University, J\&K, India

Corresponding author: Dr. Yasmeen Jabeen Bhat, E-mail: yasmeenasif76@gmail.com

\begin{abstract}
Cutaneous mastocytosis are a group of disorders which are characterized by abnormal proliferation and accumulation of mast cells in the skin. We report a case of a 21 year old female who presented with few isolated lesions on the thigh which were initially misdiagnosed as hypertrophic scars by a general practitioner. However, following examination of the case by a dermatologist, a diagnosis of cutaneous mastocytoma was suspected and confirmed with histopathological examination.
\end{abstract}

Key words: Mastocytosis; Hypertrophic scar

\section{INTRODUCTION}

Mast cell is a type of granulocyte derived from myeloid stem cells. Once thought to be tissue resident basophils, mast cells have been shown to have a unique lineage. The mast cells have a diverse distribution inhabiting the skin, respiratory, gastrointestinal and genitourinary system [1]. Although best known for their role in allergy and anaphylaxis, mast cells are now known to have critical proinflammatory as well as immunoregulatory roles and are intimately linked with wound healing, angiogenesis and blood-brain barrier function [2]. Mast cells exert their functions by means of various medaitors like histamine, leukotrienes, chemokines, cytokines, chymase and tryptase among others.

Mastocytosis is a disorder characterized by abnormal mast cell proliferation and accumulation within various organs, most commonly the skin when it is called cutaneous mastocytosis. There are three main types of cutaneous mastocytosis: maculopapular cutaneous mastocytosis, solitary cutaneous mastocytosis and diffuse cutaneous mastocytosis [3]. Telengiectasia macularis eruptive perstans is regarded as a rare variant of cutaneous mastocytosis.

The clinical presentation of cutaneous mastocytosis is diverse with lesion morphology varying from macules, papules, plaques and nodules, size ranging from few millimeters to several centimeters, and colour differing from yellow-tan to red-brown. We report a case of cutaneous mastocytosis masquerading as hypertrophic scars.

\section{CASE REPORT}

A 21 year old female patient presented to the outpatient department (OPD) of the department of dermatology of our hospital with the chief complaints of few raised reddish brown to black lesions on the right thigh from 3 months. The lesions were associated with moderate to severe pruritus which would disturb the routine activities of the patient and mandate the use of over the counter antihistaminics for relief. The patient also gave history of non-specific diffuse pruritus which would occur occasionally and had a

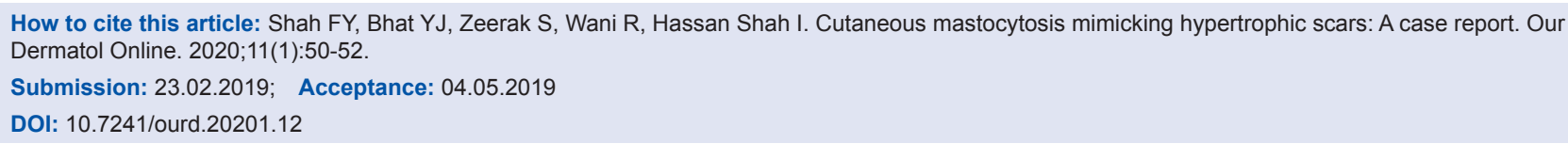


long history of many years. Rest of the history was unremarkable and there was no specific pointer to any other systemic involvement like gastrointestinal, cardiovascular, respiratory, etc. Local examination revealed the presence of two erythematous plaques and a linear erythematous plaques on the inner aspect of the right thigh (Fig. 1). The lesions were well defined with a regular hyperpigmented border. The nodules were approximately $1.5 \mathrm{~cm}$ in diameter and the plaque was approximately $5 \mathrm{~cm}$ along the long axis and $1 \mathrm{~cm}$ in width. The plaque had a brown black hue. The lesions were firm to hard on palpation and had been previously misdiagnosed as hypertrophic scar by some general practitioner. The surrounding skin was normal and no excoriations could be appreciated. Darier's sign was elicited over the lesions and the overlying skin turned red on stroking. The patient also had symptomatic dermographism which explained the diffuse pruritus that the patient complained of.

Laboratory investigations (CBC, LFT, KFT) done by the patient were within normal limits. A $5 \mathrm{~mm}$ punch biopsy was taken from the lesion and sent for histopathological examination which showed diffuse infiltration of the dermis by inflammatory cells with an unremarkable epidermis (Fig. 2). With higher magnification, collection of mast cells in the dermis alongside collections of eosinophils and lymphocytes could be appreciated (Fig. 3). Serum tryptase level was done in the patient and found to be within normal limits. A diagnosis of cutaneous mastocytosis was made in the patient.

Prior to the study, patient gave written consent to the examination and biopsy after having been informed about the procedure.

\section{DISCUSSION}

Cutaneous mastocytosis is a type of mastocytosis that primarily affects the skin. It is caused by KIT gene mutations, which are mostly sporadic and rarely inherited [4]. A diagnosis is generally suspected based on history and presence of typical lesions. Histopathological examination is generally diagnostic for cutaneous mastocytosis.

In this case, we came across a variable presentation of cutaneous mastocytosis. Even though a detailed history and examination made us suspect the diagnosis of cutaneous mastocytosis, examination by a

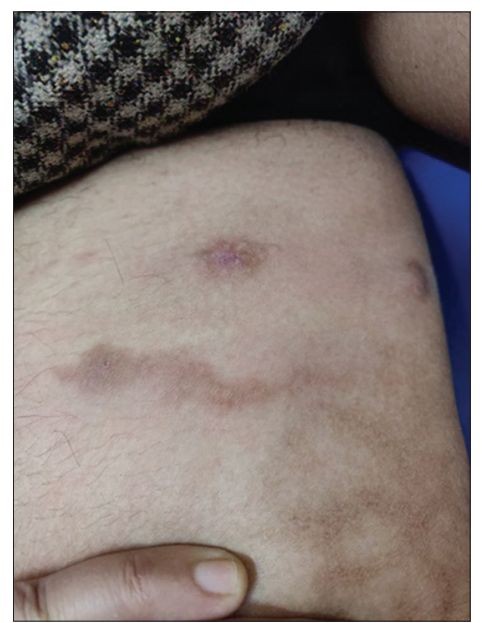

Figure 1: Mastocytoma: Two erythematous nodules and a single hyperpigmented plaque on the inner aspect of the thigh.

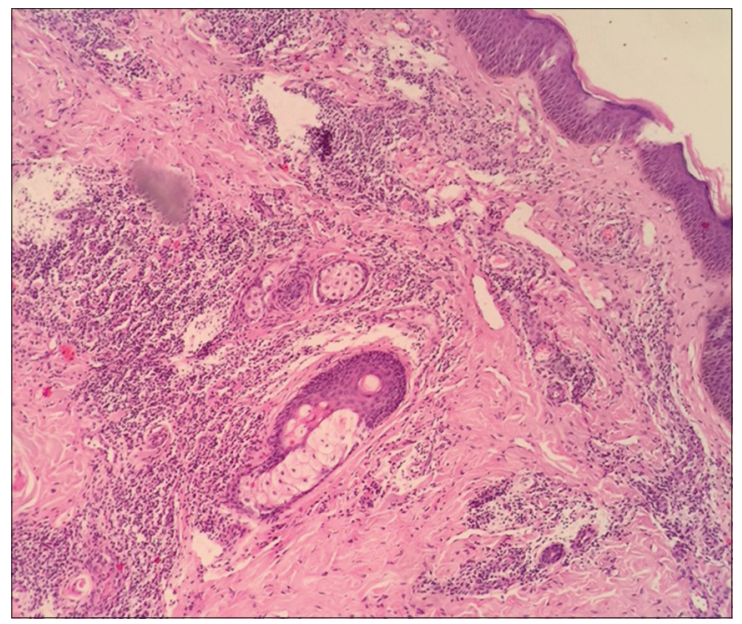

Figure 2: Photomicrograph showing aggregates of inflammatory cells extending into entire dermis with unremarkable epidermis. (100X magnification).

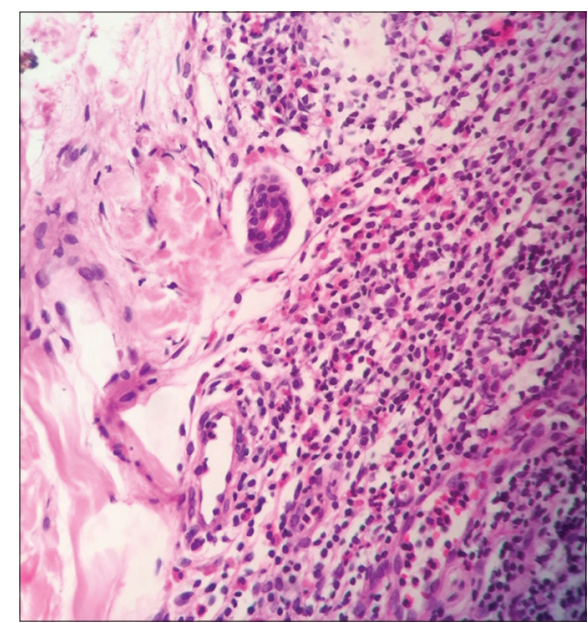

Figure 3: Collection of mast cells, eosinophils and lymphocytes in the dermis adjacent to the skin adnexae.

non-specialist landed her with an ostensible diagnosis of hypertrophic scars. The clinical appearance of 
the lesions could fit into the diagnosis of cutaneous mastocytoma but the consistency of the lesions is said to be rubbery [5], unlike our patient whose lesions were rather firm in consistency.

Disorders masquerading as closely related or unrelated mimics can be a source of puerile inaccuracies on part of the treating physician and land the patient in great misery for the want of an appropriate diagnosis and proper treatment. A careful consideration of the patient history, a meticulous examination and a mind that leaves no possibility forsaken is of utmost importance in the clinical practice of diagnosis and treatment.

\section{Consent}

The examination of the patient was conducted according to the Declaration of Helsinki principles.

\section{REFERENCES}

1. Inamadar A, Palit A. Cutaneous mastocytosis: Report of six cases. Indian J Dermatol, Venereol and Leprol. 2006;72:50.

2. Theoharides TC, Kalogeromitros D. The critical role of mast cells in allergy and inflammation. Ann NY Acad Sci. 2006;1088:78-99.

3. Hartmann KA, Henz BM. Cutaneous mastocytosis - clinical heterogeneity. Int Arch Allergy Immunol. 2002;127:143-6.

4. Longley JB, Metcalfe DD, Tharp M, Wang X, Tyrrell L, Lu S, et al. Activating and dominant inactivating c-KIT catalytic domain mutations in distinct clinical forms of human mastocytosis. PNAS. 1999;96:1609-14.

5. Cather JC, Menter AM. Red-brown skin lesions and pruritus. Proc (Bayl Univ Med Cent). 2000;13:297-9.

Copyright by Faizan Younus Shah, et al. This is an open-access article distributed under the terms of the Creative Commons Attribution License, which permits unrestricted use, distribution, and reproduction in any medium, provided the original author and source are credited.

Source of Support: Nil, Conflict of Interest: None declared. 